\title{
Glosario de términos relacionados con el deterioro de las piedras de construcción
}

J. ORDAZ y R. M. ESBERT

Departamento de Geologia, Universidad de Oviedo 33080-OVIEDO/España

Fecha de recepción: $11 / 111 / 88$

\section{INTRODUCCION}

El objetivo de este Glosario es presentar una serie de términos utilizados corrientemente en los estudios sobre la alteración de las rocas como materiales de construcción y, en particular, en los de deterioración de las piedras de los monumentos.

Dichos términos aluden a diferentes aspectos (procesos, fenómenos, mecanismos, etc.), aun cuando la mayor parte de ellos son de carácter descriptivo, y se refieren a estados y formas de alteración macroscópicas de las piedras, detectables a simple vista.

De cada término seleccionado se da una sucinta definición y se mencionan términos sinónimos o relacionados (T.r.). Algunos de ellos constituyen vocablos nuevos o adaptados al caso, sin que esto presuponga imposición de ninguna clase, quedando el Glosario abierto a ulteriores ampliaciones o modificaciones tanto conceptuales como terminológicas.

La confusión reinante sobre determinados términos, así como la disparidad de criterios expresados según países y autores, hace que toda nomenclatura de este tipo tenga que verse, hoy por hoy, con las debidas cautelas y reservas. Al no existir todavía una terminología homologada o ampliamente aceptada, la presente selección léxica no puede, ni pretende ser, dogmática o exclusivista; habiéndose recogido, simplemente, aquellos vocablos y acepciones más comúnmente empleados en la literatura específica actual sobre el tema. En cualquier caso, hay que hacer hincapié en el carácter estrictamente informativo y provisional de esta recopilación.

\begin{abstract}
Abrasión
Desgaste de la superficie de los materiales rocosos, por fricción o impacto, originado por la acción de los agentes erosivos (viento, lluvia, etc.). T.r.: Erosión, corrasión.
\end{abstract}

\section{Acanaladura}

Excavación que proporciona a la superficie de la piedra un aspecto ondulado o acanalado. Viene favorecida por las heterogeneidades de la roca (presencia de capas, hiladas o zonas menos duras, "blandones" en cantería); por la acción dirigida de las aguas pluviales y desagües; o por el asiento (a "hoja" o a "contrahoja") del sillar en el edificio. T.r.: Estriadura.

\section{Alterabilidad}

Tendencia de un material rocoso a alterarse, generalmente a corto plazo (escala histórica o humana). Es concepto inverso al de durabilidad. T.r.: Meteorabilidad, Alteración.

\section{Alteración}

Modificación o cambio en la composición química o mineralógica de un material pétreo, producido por los agentes meteóricos. T.r.: Meteorización, Deterioro.

\section{Alterografía}

Descripción de las formas y estados de alteración o deterioro de las piedras. T.r.: Alterología.

\section{Alterologia}

Estudio de las formas y fenómenos de alteración de las piedras, as como de sus causas y mecanismos. T.r.: Alterografía.

Alveolar (erosión)

Véase Alveolización

\section{Alveolización}

Degradación de origen físico-químico, en forma de alveolos, característica de ciertos materiales rocosos granudos y porosos (tobas, areniscas, etc.). Erosión alveolar, o en panal de miel ("honeycomb weathering"). Tafonización. T.r.: Alveolo, Tafone. 


\section{Alveolo}

Cavidades $\mathrm{u}$ oquedades de forma más o menos globular, interconectadas o no, y que en conjunto adquieren un aspecto de panal de miel. El interior de los alveolos suele albergar material disgregado, eflorescencias, microorganismos, etc. T.r.: Alveolización, Tafone.

\section{Ampolla}

Despegue más o menos abombado, con ahuecamiento interno, de costras, eclosionadas o no. T.r.: Costra, Descamación. Decorticación.

\section{Antrópico (deterioro)}

Degradación o destrucción de materiales pétreos causada por la acción de los hombres (mutilaciones, incisiones, etc.). T.r.: Excoriación.

\section{Arenización}

Tipo de meteorización caracterizado por la caída "grano a grano", espontánea o inducida, de materia tamaño arena. Desagregación granular. T. r.: Descohesión, Pulverización.

\section{Biodegradación}

Deterioro producido por la acción biológica.

\section{Biodeterioración}

Véase Biodegradación.

\section{Burilado}

Acción y efecto de quedar pulimentadas las piedras, bien por causas naturales (corrasión), bien por otros medios (p. ej. fricción antrópica).

\section{Carbonatación}

Alteración química que comporta la transformación de minerales conteniendo calcio, sodio, hierro magnesio. potasio..., en carbonatos y bicarbonatos de estos elementos metálicos, por acción del dióxido de carbono disuelto en el agua. T.r.: Alteración.

\section{Caverna}

Cavidad de gran tamaño producida principalmente, en piedras calcá reas, por disolución kárstica. T.r.: Microkarst.

\section{Concreción}

Depósito o masa de agregados minerales, de dimensiones limitadas; producto, generalmente, de la precipitación del carbonato cálcico de las aguas duras; o de la recristalización, en la superficie del material, de carbonato cálcico proveniente del substrato. T.r.: Incrustación.

\section{Contracción}

Reducción del volumen de una piedra, ya sea por desecación (disminución del contenido en humedad natural o de reabsorción), o por otras causas (p. ej. efectos térmicos). T.r.: Expansión.

\section{Corrasión}

Acción erosiva, mecánica, del viento cargado con partículas sólidas (especialmente granos de cuarzo). T.r.: Erosión eólica, abrasión.

\section{Corrosión}

Deterioro gradual de un material por agentes químicos. Corrosión atmosférica: la provocada por los componentes del aire o sustancias contaminantes del mismo. Corrosión biológica: la provocada por la actividad metabólica de organismos vivos.

\section{Costra}

Lámina compacta de material en la parte externa de una piedra, producto de una transformación superficial, y cuya naturaleza químicomineralógica y características físicas son parcial o totalmente distintas de las del substrato pétreo sobre el que se asientan. Visualmente se distinguen, en general, por sus rasgos morfológicos (a veces en forma de caparazón), dureza (se hallan endurecidas con respecto al material rocoso alterado); $y$, a menudo, por su color (costras negras) al contener productos carbonosos de contaminación (hollín, polvo, etc.). T.r.: Concreción, Incrustación, Pátina.

\section{Crioclastia}

Fisuración o fragmentación de las piedras como consecuencia de los efectos del hielo-deshielo. T.r.: Crioclasticidad, heladicidad.

\section{Crioclasticidad}

Véase Heladicidad.

\section{Criptoflorescencia}

Agregados cristalinos situados más internamente en la piedra que las subflorescencias. T.r.: Eflorescencias, Subflorescencia.

\section{Cromática (alteración)}

Alteración caracterizada por una variación en el lustre o brillo ("lightness"), en el matiz ("hue") o en la saturación del color ("chroma") de una piedra. T.r.: Cromatización, Rubefacción, Decoloración.

\section{Cromatización}

Cambios o modificación en el color original de la piedra, debido a procesos de alteración química. T.r.: Alteración cromática.

\section{Chancro}

Especie de cavidad en la piedra, con una parte vacia interna, y una corona externa (o anillo "cicatricial"), más o menos duro. T.r.: Ampolla.

\section{Decoloración}

Debilitamiento o pérdida de color de un material expuesto a la intemperie. T.r.: Alteración cromática, Pátina.

\section{Decorticación}

Acción y efecto de levantar, natural o artificialmente, las escamas o costras formadas en la superficie de una piedra. T.r.: Descamación, Descostración.

\section{Deformación plástica}

Deformación penetrativa de la forma o volumen de una piedra, de 
carácter irreversible y permanente. La deformación plástica conduce a alabeos, combas y similares; sobre todo en losas, lápidas o planchas de mármol.

\section{Degradabilidad}

Tendencia a la degradación por parte de un material pétreo. Véase Alterabilidad.

\section{Degradación}

Véase Deterioro.

\section{Depósito superficial}

Acumulación de material de origen diverso (polvo, humos, hollín, guano, microorganismos, etc...) en la superficie de una piedra. Normalmente de escasa cohesión, espesor variable y baja adherencia al substrato sobre el que se asienta. T.r. Enmugrecimiento.

\section{Derrubio}

Material desagregado, terroso, que se cae o se desmorona de una piedra, y que se acumula en el suelo. T.r.: Arenización, Pulverización.

\section{Desagregación}

Alteración física (mecánica), que comporta generalmente un debilitamiento de las cualidades resis tentes de una piedra, y que se traduce generalmente en una pérdida de material (granos). T.r.: Arenización, Pulverización, Descohesión.

\section{Desagregación arenosa}

Véase Arenización.

\section{Desagregación pulverulenta}

Véase Pulverización.

\section{Descamación}

Levantamiento y separación de escamas paralelamente a la superficie de la piedra, por causa de diferentes mecanismos (cambios de temperatura o humedad, acción del hielo o de las sales, etc...). T.r.: Decorticación, Desplacación.

\section{Descementación}

Disminución o pérdida de cemento o matriz de un material por procesos de disolución. La descementación conduce generalmente a la desagregación granular. T.r.: Desagregación.

\section{Descohesión}

Disminución o pérdida de la cohesión o adherencia entre los granos o componentes texturales o estructurales de una piedra. Normalmente conduce a un aumento de la porosidad o microfisuración, y a una reducción de la resistencia mecánica. T.r.: Desagregación, Descementación.

\section{Descomposición}

Alteración química. Cambio en la composición química o mineralógica de una piedra. T.r.: Alteración, Meteorización.

\section{Desconchadura}

Separación y caída de trozos o fragmentos superficiales de material pétreo, enlucidos, revocos, etc. T.r.: Descamación, Exfoliación.

\section{Descostración}

Levantamiento y separación de costras. T.r.: Costra, Decorticación.

\section{Desmoronamiento}

Desagregación o colapso físico de una piedra o conjunto de piedras, por pérdida total de la cohesión entre sus componentes o partes. T.r.: Desagregación, Ruina.

\section{Desplacación}

Levantamiento y separación de placas. T.r.: Placa.

\section{Deterioración}

\section{Véase Deterioro.}

\section{Deterioro}

Modificación o cambio del material pétreo que implica un empeora- miento o declinación de sus características físicomecánicas, desde el punto de vista de su conservación. El deterioro diferencial es el deterioro desigual, condicionado por la heterogeneidad en la composición, textura o estructura del material rocoso, y que da lugar a niveles de degradación distintos dentro de una misma piedra. La existencia de distintos niveles de degradación de los materiales pétreos, dentro de un conjunto de éstos (p. ej. en un mismo paramento o muro) constituye un deterioro selectivo. T.r.: Degradación.

\section{Dilatabilidad}

Véase Expansibilidad.

\section{Disolución}

Acción y efecto de disolverse un material, generalmente por las aguas meteóricas. Afecta principalmente a las rocas calcáreas y a las detríticas con cementos carbonatados o arcillosos. T.r.: Carbonatación, Descementación.

\section{Durabilidad}

Resistencia de un material a alterarse, generalmente a corto plazo. Concepto inverso al de Alterabilidad. T.r.: Alteración.

\section{Eflorescencia}

Capa o formación de cristales de sales solubles, de color blanquecino, no muy consistente, que se forma en la superficie de una piedra porosa, debida a fenómenos de migración y evaporación de agua conteniendo sales solubles. T.r.: Subflorescencia, Criptoflorescencia.

\section{Enmugrecimiento}

Depósito superficial, generalmente de color oscuro o negro, formado por la acumulación de polvo, hollín, humos, vegetaciones, etc. Suciedad superficial: tizne. T.r.: Depósito superficial, Pátina.

\section{Erosión}

Término genérico que se aplica a los procesos físicos, químicos y biológicos que conducen al rebaja- 
miento del relieve y pérdida de material (p. ej. alveolización, corrosión, abrasión, etc...). T.r.: Meteorización.

\section{Escama}

Lámina o plaquita más 0 menos compacta, de unos pocos milíme tros de espesor, que se desprende paralelamente a la superficie de la piedra, e independientemente de la estructura de la misma. T.r.: Descamación, Placa.

\section{Estriadura}

Excavaciones delgadas en forma de estrías o rasgaduras. Se deben, principalmente, a heteogeneidades del material, ahondadas por los efectos dirigidos de las aguas pluviales. T.r.: Acanaladura.

\section{Excoriación}

Desolladura o rasgadura en la superficie de un material pétreo, por la acción más o menos violenta de frotamientos o incisiones de carácter antrópico. En sentido laxo: desprendimiento de capas superficiales alteradas. T.r.: Deterioro antrópico.

\section{Exfoliación}

Acción de exfoliarse una roca. Levantamiento y separación de una o más lascas o capas (alteradas o no), de espesor uniforme (varios milimetros), paralelamente entre $s$ y a planos estructurales o de debilidad de la piedra (foliaciones, discontinuidades...). Separación a "hoja" de un sillar. T.r.: Desplacación, Lajamiento.

\section{Expansibilidad}

Capacidad de expandirse o dilatarse una piedra por diversas causas (expansión hídrica, térmica, etc...). T.r.: Expansión, Contracción.

\section{Expansión hídrica}

Dilatación o aumento de volumen de una piedra producido por la absorción de agua líquida. El hinchamiento viene favorecido normalmente por la presencia en la piedra de determinados minerales arcillosos expansivos (p. ej. esmecti- tas). Los ciclos de expansión/retracción suelen conducir a diversos tipos de deterioro (fisuración, desagregación granular, descamación, etc.). T.r.: Expansión hígrica.

\section{Expansión higrica}

Dilatación o aumento de volumen de una piedra producido por absorción higroscópica de vapor de agua. T.r.: Expansión hídrica.

\section{Expansión térmica}

Dilatación o aumento de volumen de una piedra producido por incremento de temperatura. Los ciclos térmicos conducen generalmente a deterioros de diversa índole (fisuración, desagregación granular...). T.r.: Termoclastia.

\section{Exudación}

Movilización y deposición en superficie de sales solubles. T.r.: Eflorescencia, Haloclastia.

\section{Fisibilidad}

Propiedad de algunos materiales arcillosos (p. ej. pizarras) de exfoliarse o separarse en "hojas" o placas más o menos finas, paralelas entre sí, y siguiendo los planos de pizarrosidad. Tegulismo. T.r.: Exfoliación, Lajamiento.

\section{Fisilidad}

Véase Fisibilidad.

\section{Fisura}

Discontinuidad planar, macroscópica o microscópica (microfisura), de diverso origen y dimensiones variables. En general, fractura o hendedura en la masa de una piedra. Se pueden distinguir varios tipos: las fisuras preexistentes, originales de la roca ("pelos" en canteria); las producidas durante la extracción, labra, esculpido, aserrado o manipulación en general de una piedra ("artefactos"): las generadas a consecuencia de esfuerzos mecánicos derivados de la estructura del edificio (p. ej. asentamiento defectuoso de un sillar, anclajes internos, etc...); y las inducidas por los ciclos térmicos, de hielo-deshielo, de humedad-sequedad. etc. T.r.: Fractura.

\section{Fisuración}

Deterioro o degradación caracterizada por la presencia de fisuras en la piedra. T.r.: Fisura, Fractura.

\section{Forma (de alteración)}

Aspecto o modo de presentación característico de un determinado tipo de alteración o deterioro.

\section{Fotodegradación}

Degradación producida por la radiación, principalmente visible y ultravioleta de la luz solar. Afecta asimismo o los productos orgánicos de tratamiento de las piedras. Degradación fotooxidativa.

\section{Fotodeterioración}

Véase Fotodegradación.

\section{Fractura}

Superficie de discontinuidad resultado, por lo general, de esfuerzos de tracción o de cizalla. T.r.: Fisura.

\section{Fracturación}

Véase Fisuración.

\section{Friabilidad}

Calidad de friable o desmenuzable. Característica de materiales incompetentes, poco resistentes o fuertemente alterados.

\section{Gelifracción}

Fragmentación de un material pétreo por la acción disruptiva del hielo. T.r.: Crioclastia, Heladicidad.

\section{Grieta}

Fisura o fractura abierta, normalmente de gran tamaño. T.r.: Fisura.

\section{Haloclastia}

Fisuración o fragmentación de un material por acción de la cristalización de sales solubles. T.r.: Exudación. 
Heladicidad

Susceptibilidad de un material a la acción del hielo. Crioclasticidad. T.r.: Heladizo, Gelifracción.

\section{Heladizo}

Dícese de un material pétreo que es sensible o propenso a la acción del hielo. T.r.: Crioclastia, Gelifracción. Heladicidad.

\section{Herrumbre}

Véase Orín.

\section{Hidratación}

Incorporación de agua en la composición química de un mineral. La fragmentación por hidratación ("hydration shattering") consiste en la separación y quebrantamiento de un material rocoso por la presión de cuña ejercida por películas de agua de espesor variable sobre las superficies de minerales silicatados. Esta acción puede verse intensificada por ciclos de hielo-deshielo. T.r.: Desagregación, Desmoronamiento.

\section{Hidrólisis}

Alteración química o descomposición de una substancia mineral por el agua. Afecta fundamentalmente a los silicatos, siendo los productos finales de reacción minerales arcillosos (caolinización, sericitación, etc). T.r.: Descomposición.

\section{Higroscopicidad}

Capacidad de absorción de humedad ambiental (vapor de agua) por parte de un material pétreo. T.r. Expansión hígrica.

\section{Hinchamiento}

Véase Expansión hídrica.

\section{Humectación}

Acción y efecto de humedecer. Zona o mancha de humedad visible exteriormente, debida a la acumulación y retención de agua por parte de la piedra (especialmente en muros y paramentos).

\section{Incoherencia}

Deterioro, no siempre visible a simple vista, consistente en un debilitamiento de las uniones intergranulares y componentes estructurales de la piedra, que implica generalmente un incremento de la porosidad y microfisuración. En último término conduce a la desagregación y a la reducción de la resistencia mecánica. T.r.: Desagregación, Descohesión.

\section{Incrustación}

Depósito lenticular o estratiforme, compacto y adherente al substrato pétreo. Generalmente está formada por compuestos carbonatados o sulfatados. En calizas las incrustaciones pueden deberse a la recristalización de carbonato cálcico de la roca, disuelto y reprecipitado a partir de agua conteniendo dióxido de carbono. T.r.: Concreción.

\section{Lajamiento}

Levantamiento y separación de placas o lajas paralelamente a la superficie del material. Usase también como sinónimo de desplacación y exfoliación.

\section{Lavado (zona de)}

Parte exterior de una piedra o conjunto de piedras, exenta de costras, depósitos superficiales o pátinas de enmugrecimiento, por la acción repetida de las aguas de lluvia dirigidas o canalizadas. T.r.: Lixiviación.

\section{Lixiviación}

Separación, remoción selectiva o disolución de componentes solubles de una piedra, por la acción de las aguas percolantes. Lavado de la superficie externa de las piedras. T.r.: Zona de lavado.

\section{Meteórica (alteración)}

Alteración debida a la acción de agentes atmosféricos (lluvia, viento, etc....). T.r.: Meteorización.

\section{Meteorización}

Conjunto de procesos químicos, físicos y biológicos naturales con- ducentes a la desagregación mecánica y descomposición química, generalmente a largo plazo, de los materiales rocosos expuestos a los efectos de la intemperie. En ocasiones se utiliza como sinónimo de alteración (atmosférica o meteórica). T.r.: Degradación, Alteración.

\section{Meteorabilidad}

Véase Alterabilidad.

\section{Microdescamación}

Descamación de tamaño microscópico. T.r.: Descamación.

\section{Microfisuración}

Fisuración de tamaño microscópico. Microfracturación. T.r.: Fisuración.

\section{Microkarst}

Conjunto de formas (cavidades), a pequeña escala, debidas a la disolución por agua de materiales calcáreos. T.r.: Disolución Kárstica.

\section{Moteado}

Presencia de pequeñas áreas de pigmentación variable, generalmente de naturaleza orgánica (biológica).

\section{Orín}

Herrumbre. Pátina de tinción rojizo-amarillenta producida por óxidos de hierro (hematites, limonita) de algunos materiales pétreos, o bien por la oxidación de elementos metálicos de la edificación en contacto con las piedras. T.r.: Pátina.

\section{Oxidación}

Reacción química del oxígeno con una substancia mineral, con formación generalmente de óxidos. Los minerales ferruginosos de las piedras se oxidan con facilidad, dando lugar a alteraciones cromáticas y pátinas de tinción. El incremento de volumen de los óxidos resultantes puede contribuir, asimismo, a la formación de descohesiones y desagregaciones granulares. T.r.: Alteración. 


\section{Pátina}

Capa o película superficial y delgada que se forma sobre las piedras por diversas causas. Modificación superficial del material que no implica necesariamente procesos de degradación o deterioro. El término genérico de "pátina" incluye varias acepciones:

a) Tonalidad o aspecto externo que cualquier piedra adquiere por "envejecimiento" con el paso del tiempo, y bajo los efectos de la intemperie.

b) Decoloración debida a causas naturales o artificiales.

c) Película coloreada artificial (patinación).

d) Película de carácter orgánico (p. ej. algas) de tonalidad variable (pátina biológica).

e) Teñido superficial debido a diversas substancias: orín, verdín, etc...(pátina de tinción).

f) Acumulación superficial de suciedad (pátina de enmugrecimiento).

\section{Picadura}

Erosión o corrosión puntiforme caracterizada por la formación de pequeños orificios o cavidades en el material pétreo. T.r.: Alveolización.

\section{Placa}

Lámina compacta, más o menos alargada, de varios milimetros de espesor. T.r.: Escama, Desplacación.

\section{Pulverización}

Tipo de degradación caracterizado por la caída espontánea o inducida de material pulverulento. T.r.: Pulverulencia, Arenización.

\section{Pulverulencia}

Zona o parte de una piedra caracterizada por la presencia de finas capas de material en estado pulverulento. T.r.: Pulverización.

\section{Retracción}

Véase Contracción.

\section{Rubefacción}

Enrojecimiento más o menos superficial de la piedra debido, sobre todo, a la tinción por óxidos de hierro propios del material rocoso. T.r.: Alteración cromática.

\section{Ruina}

Nivel muy elevado de deterioro destrucción o abandono de un conjunto de piedras o fábrica.

\section{Sacarificación}

Desagregación o arenización de materiales rocosos con textura sacaroidea (p. ej. mármoles). T.r.: Desagregación granular, Arenización.

\section{Subflorescencia}

Agregado cristalino, de carácter salino, situado por debajo de la superficie de una piedra, pero muy cerca de ella. T.r.: Eflorescencia, criptoflorescencia.

\section{Sulfatación}

Alieración química que comporta la formación de sulfatos, anhidros o hidratados, generalmente a partir de reacciones del dióxido de azufre de la atmósfera con substancias minerales de la piedra. Pueden presentarse en forma de agregados cristalinos (eflorescencias) o de costras. T.r.: Yesificación.

\section{Tafone}

Caverna o alveolo de grandes dimensiones. Plural: Tafoni (it.) o "tafones". T.r.: Alveolo, Caverna.

\section{Tafonización}

Formación de "tafones" en piedras o conjuntos de piedras. Se utiliza, en ocasiones, como sinónimo de alveolización (sobre todo en las de gran desarrollo). T.r.: Erosión alveolar, Tafone.

\section{Tegulismo}

Véase Fisibilidad. Se aplica, en especial, a las pizarras de techar.

\section{Termoclastia}

Fisuración o fragmentación de un material pétreo producida por la acción repetida de ciclos de expansión-contracción térmica. T.r.: Expansión térmica.

\section{Tizne}

Véase Enmugrecimiento.

\section{Vegetación}

Crecimiento de plantas de diversas clases (hierbas, arbustos, etc) entre los intersticios y juntas de las piedras, con efectos generalmente destructivos. T.r.: Erosión vegetal.

\section{Vegetal (erosión)}

Erosión biológica debida a la acción de organismos vegetales (algas, hongos, líquenes, musgos, etc.) que crecen sobre, o entre, las piedras. T.r.: Vegetación.

\section{Vermiculadura}

Estriadura o acanaladura sinuosa y delgada, semejante a huellas de gusanos, en la superficie de la piedra. T.r.: Estriadura, Acanaladura.

\section{Yesificación}

Formación de yeso (sulfato cálcico dihidratado), generalmente en forma de costras superficiales. T.r.: Sulfatación. 


\section{BIBLIOGRAFIA}

Para la elaboración de este Glosario se han tenido en cuenta, básicamente, además de otros libros y artículos sobre el tema, los siguientes documentos:

ARNOLD, A.; JEANETTE, D. y ZEHNDER, K.: Proposal for a Terminology of Weathering Phenomena on Building Stones, Work Document, Group Petrography, Zurich-Strasbourg, 1980.

BATES, R. L. y JACKSON, J. A. (Eds.): Glossary of Geology, American Geological Institute, 2nd. Ed., Falls Church, Va., 1980.

C. N. R. - I. C. R.: Alterazzioni macroscopiche dei materiali lapidei: lessico, Raccomendazioni NORMAL, 1-80, Roma, 1980.

HENAU, P.: Vocabulaire des terms descriptifs de l'état de surface des matériaux de construction, Institut Royal du Patrimoine Artistique, Bruselas, 1980.

LAZZARINI, L.: Lessico, En: “La pulitura dei materiali lapidei da costruzzione e scultura”, CEDAM-Casa editrice Dott. Antonio Milani, Padua, 1981.

ORDAZ, J.: Glosario de términos relacionados con las formas y fenómenos de deterioración de las piedras de los monumentos. Informe Interno A. 01/82, Departamento de Petrología y Geoquímica, Oviedo, 1982.

REAL ACADEMIA DE CIENCIAS EXACTAS. FISICAS Y NATURALES: Vocabulario científico y técnico. Madrid. 1983.

\section{AGRADECIMIENTO}

A la Comisión Asesora de Investigacion Científica y Técnica (CAICYT) y a la Fundación Ramón Areces, por la financiación de proyectos relacionados con este tema.

\section{publicación del I.E.T.c.C.}

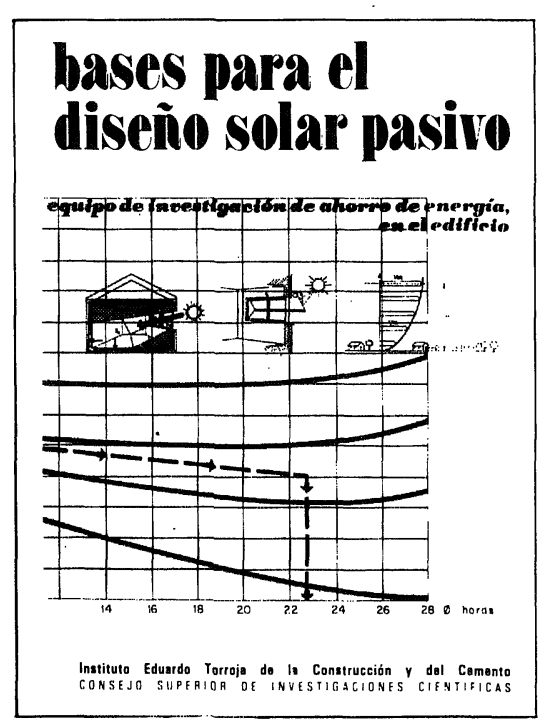

Equipo de Ahorro de Energía en el edificio

Dirección y coordinación:

Arturo García Arroyo

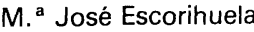

José Luis Esteban

José Miguel Frutos

Manuel Olaya

Bernardo Torroja
Las dificultades de suministro $y$ el alto coste de los productos energéticos convencionales han despertado la atención de los usuarios, técnicos $\mathrm{e}$ industriales de la edificación hacia los procedimientos y sistemas en que se basa el aprovechamiento de otras fuentes alternativas de energía, principalmente la solar. Esto ha generado un rapido desarrollo industrial $y$ comercial que, en opinión de los autores de este libro, arrastran los siguientes defectos: un mimético tecnologismo respecto de los sistemas convencionales que violenta las peculiaridades de la energia solar (baja densidad $y$ variabilidad en el tiempo), y una escasa selectividad en la aplicación de los sistemas y procedimientos pasivos dando origen a un ecumenismo arquitectónico solar, al margen de las condiciones climáticas y funcionales especificas de cada caso y lugar

En este libro, utilizando criterios y metodologia pedagógicos, se dan los fundamentos e instru mentos teórico-prácticos necesarios para el planteamiento de todo proyecto arquitectónico solar pasivo de acuerdo con los principios éticos y económicos de conservación y ahorro de energía. Es decir: respeto de los presupuestos bioclimáticos, búsqueda de la máxima captación y acumulación de la radiación solar, y esmero en el aislamiento térmico de los cerramientos.

Un volumen encuadernado en cartulina ibiza plastificada, a cinco colores, de $16 \times 23 \mathrm{~cm}$, compuesto de 216 páginas, 217 figuras, 87 gráficos, 19 tablas y 10 cuadros.

Madrid, 1983. Precios: España 2.100 ptas.; 30 \$ USA 